\title{
LEY DE VÍCTIMAS Y RESTITUCIÓN DE TIERRAS Un desafío al reconocimiento de los principios de verdad, justicia, reparación y no repetición ${ }^{1}$
}

Victims and Land Restitution Law. A challenge to the Recognition of the Principles of Truth, Justice, Reparation and no Repetition ${ }^{1}$

\section{Melisa José Caro Benítez ${ }^{2}$ Cristian García Watts ${ }^{3}$}

Fecha de Recepción: Mayo 6 e 2013

Fecha de Aceptación: Mayo 13 de 2013

SUMARIO: 1. Introducción; 2. Teoría de la justicia transicional y su aplicación en Colombia; 3. Principios protegidos por la justicia transicional; 4. Clases de justicia transicional aplicadas en el mundo; 5. Análisis de ley de víctimas y restitución de tierras, Ley 1448 de 2011; 6. Materialización del fenómeno de la discriminación positiva en la ley de víctimas y restitución de tierras; 7. Conclusiones; Referencias bibliográficas.

${ }^{1}$ Avance de investigación denominada: "Justicia transicional en el estado colombiano". Del Grupo de Investigación filosofía del derecho, derecho internacional y problemas jurídicos contemporáneos. Universidad de Cartagena.

${ }^{2}$ Abogada Universidad de Cartagena, Auxiliar judicial Tribunal Superior del distrito Judicial de Cartagena, Sala Civil Especializada en Restitución de Tierras, E-Mail:mel-0319@hotmail.com.

${ }^{3}$ Estudiante de Derecho Universidad de Cartagena, E-Mail: cristian.garciawatts@ hotmail.com. 


\section{COMO CITAR ESTE ARTíCULO (APA 6th)}

Caro Benítez, M., García Watts, J. C. (2013) Ley de víctimas y restitución de tierras. Un desafío al reconocimiento de los principios de verdad, justicia, reparación y no repetición. (Y. Carrillo De la rosa, Ed.) Revista Mario Alario D'filippo V(10), págs. 99-107

\section{RESUMEN}

Colombia es uno de los países que se encuentra en etapa de transición, sin que haya terminado aún el conflicto armado que lo sacude; hoy está vigente una ley que pretende restablecer integralmente a las víctimas, resarcir los daños causados y ayudarlos a superar la situación de vulnerabilidad en que se encuentran. Pero detrás de esta ley se mueven diversos intereses de carácter político y económico, a través de los cuales se pretende influir en la aplicación de la ley; además, plantea esta ponencia que la ley de víctimas y restitución de tierras genera una discriminación positiva hacia las víctimas civiles del conflicto armado.

\section{ABSTRACT}

Colombia is a country that is in transition, without having yet completed the armed conflict that shakes; today is in effect a law that aims to fully restore the victims, the damages caused and help them overcome the situation of vulnerability in which they find themselves. But behind this law diverse interests of political and economic move, through which it is intended to influence the application of the law; also raises this paper that the law of victims and land restitution creates a positive discrimination towards civilian victims of armed conflict.

\section{PALABRAS CLAVE}

Derechos, víctimas, reconocimiento, reparación, justicia.

\section{KEYWORDS}

Rights, victimize recognition, repair and justice. 


\section{INTRODUCCIÓN}

Con el presente artículo se tiene como fin explicar si la ley de víctimas y restitución de tierras, abarca todos los aspectos necesarios para lograr una eficaz protección a las víctimas del conflicto armado colombiano, se realiza un análisis crítico a ciertos aspectos importantes en la ley, donde se vislumbran vacíos jurídicos, los cuales desnaturalizan el fin único del Estado, la protección y garantía de los derechos de sus ciudadanos.

En otro punto de la investigación se abordara el tema de la discriminación positiva, que acarrea el reconocimiento que hace el Estado colombiano a los civiles víctimas del conflicto armado. Por último se expondrán las conclusiones pertinentes generadas con el desarrollo de la ponencia.

La metodología usada en esta investigación es la analítico-descriptiva; utilizando aportes doctrinarios realizados por los estudiosos y especialistas del derecho internacional humanitario y el desarrollo del conflicto armado en Colombia, citamos posiciones manifestadas por las altas cortes colombianas, las cuales día a día con sus sentencias crean derecho y sientan precedente.

Además se tomará como elemento esencial la doctrina colombiana por ser este el país referencia de la investigación exponer; para así con ayuda de la jurisprudencia internacional y nacional, las doctrinas nacional e internacional hacer una descripción analítica del problema del cual se derivó esta investigación.

\section{TEORÍA DE LA JUSTICIA TRANSICIONAL Y SU APLICACIÓN EN COLOMBIA}

Los Estados que sufren o han sufrido crisis internas como un conflicto armado, se mantienen en la constante búsqueda de mecanismos que ayuden a salir de la emergencia social en que se encuentran. Colombia uno de los países que desde los más remoto de su historia vive un conflicto armado, está en la búsqueda de una transición social (florian, 2007), Hoy está poniendo en práctica lo que muchos han denominado justicia transicional un mecanismo que tiene como fin último lograr la paz y reconciliación con el restablecimiento el estado social de derecho y el reconocimiento de los derechos de las víctimas, a través de la implementación o cumplimiento de determinados parámetros, como la búsqueda de la verdad con la confesión de hechos delictivos por parte de los perpetradores de delitos, la reparación de los perjuicios y por último la creación de justicia la cual es uno de los fines del estado social de derecho (Habermas, 1998); pues este tiene la obligación de poner a trabajar todo el aparato jurisdiccional para lograr el esclarecimiento de los hechos y a su vez castigar a los perpetradores de los delitos. (Quezada, 2010)

\section{PRINCIPIOS PROTEGIDOS POR LA JUSTICIA TRANSICIONAL}

Como método de trasformación del conflicto se han tomado como base principal los principios de verdad, justicia y reparación integral, los cuales se explicarán de la siguiente forma:

VERDAD: según JOINET (1996) "Cada pueblo tiene el derecho inalienable de conocer la verdad sobre los acontecimientos pasados, así como sobre las circunstancias y las razones 
que llevaron por la violación masiva y sistemática de los derechos humanos a la perpetración de crímenes aberrantes". La verdad comprende el derecho de preservar la memoria histórica y que las familias de las victimas conozcan la verdad en lo que concierne la suerte que fue reservada para sus parientes.

En Colombia la ley de justicia y paz en relación con la verdad, dispone que la sociedad y en especial las víctimas tienen el derecho inalienable, pleno y efectivo de conocer la verdad sobre los delitos cometidos por grupos armados organizados al margen de la Ley; y lo más importante sobre el paradero de las víctimas de secuestro y desaparición forzada. Así mismo contempla la conservación de los archivos de los hechos y circunstancias relacionados con las conductas delictivas con el fin de garantizar los derechos de las víctimas a la verdad y preservar del olvido la memoria colectiva.

La verdad es el esclarecimiento de los hechos pues el estado debe garantizar el acceso a la víctima o sus representantes a la información con el fin de posibilitar la materialización de sus derechos. Pero "Muchas veces la "verdad" se limita a la confección de listas de víctimas, a las que se acepta caracterizar como "víctimas de excesos de anónimos agentes aislados del Estado", agentes a los que luego, en su anonimato, se extenderá un "perdón reconciliador" otorgado por el mismo Estado, en nombre de una "sociedad que quiere la paz y la reconciliación". Todas las víctimas tienen derecho al conocimiento de los motivos y circunstancias en que se cometieron las infracciones siempre y cuando esto no se convierta en un método utilizado por los victimarios para lograr la impunidad de sus delitos. Aunque la aplicación del principio de verdad puede der entendida desde dos puntos de vista:

1) Como método que conocimiento de porque la realización de la conducta delictiva (esclarecimiento de los hechos), aquí la víctima encuentra respuestas a las preguntas como: ¿Por qué me he visto afectado con el conflicto? ¿Por qué desaparecieron a mis familiares?

2) Como una de las formas de llegar a la impunidad. Pues si el estado no toma las medidas necesarias para abordar el tema de la amnistía y el indulto los victimarios serán dejados en libertad por el solo hecho de revelar los actos atroces y llenos de barbarie.

JUSTICIA: Es el esclarecimiento de las violaciones, la identificación y sanción de los responsables y además en el cumplimiento de este derecho el estado tiene la obligación de brindar a las víctimas el acceso a las medidas de atención, asistencia y reparación. La aplicación de sanciones y penas a los victimarios se surte el único mecanismo con que una sociedad cuenta para defenderse de conductas y prácticas que destruyen sus posibilidades de convivencia civilizada.

Este principio "Implica que toda víctima tenga la posibilidad de hacer valer sus derechos beneficiándose de un recurso justo y eficaz, principalmente para conseguir que su opresor sea juzgado, obteniendo su reparación".

REPARACIÓN: Toda violación de los derechos humanos da nacimiento a la reparación en favor de la víctima, de sus parientes que implica, por parte del Estado. La reparación es una dimensión intrínseca de la justicia que trata de volver a equilibrar la balanza de la realidad, la cual había 
quedado ventajosamente inclinada en favor del victimario, reconstruyendo en lo posible, o recompensando en su peso, lo que el victimario destruyó, y asegurando que su poder destructor no vuelva a imponerse

En la Ley 1448 de 2011, se expresa lo siguiente:

Art. 25: ..."Con la reparación integral la victima tiene derecho a ser reparadas de manera adecuada, diferenciada, transformadora y efectiva por el daño que ha sufrido, la reparación comprende las medidas de restitución, indemnización, rehabilitación, satisfacción y garantías de no repetición en sus dimensiones individual, colectiva, material, moraly simbólica."

En cuanto al punto de la reparación integral, el gobierno ha tenido como iniciativa la implementación de una ley que pretende dar protección y garantizar los derechos de las víctimas, esta es la Ley 1448 del 2011, llamada ley de víctimas y restitución de tierras. Es el resultado de diálogos que se dieron entre víctimas, representantes de organizaciones sociales y con el acompañamiento técnico de la nación u organismos internacionales.

\section{CLASES DE JUSTICIA TRANSICIONAL APLICADAS EN EL MUNDO (ONU, 2004):}

- PERDONES AMNÉSICOS: Concesión de amnistías generales desprovistas de compromisos con la verdad o reparación de las víctimas.

- PERDONES COMPENSADORES: Conceden amnistías seguidas de la implementación de comisiones de verdad y en algunos casos de reparación de las víctimas.

- PERDÓN RESPONSABILIZANTE: Se establecen comisiones de verdad (Juristas, 2012), exigencia de verdad y reparación y otorgamiento de los perdones individuales de algunos delitos.

- TRANSICIONES PUNITIVAS: En las que se establecen tribunales ad hoc para castigar a los responsables de crímenes de guerra y lesa humanidad.

En Colombia la Ley 1448 del 2011, reconoce a los civiles como víctimas sin importar si su victimario fue la guerrilla, paramilitares o agentes del estado. Pero el concepto de víctima que se maneja en esta ley es restrictivo pues solo se pueden acoger a ella las personas que hayan sido afectadas por hechos surgidos a partir del 1 de enero de 1985 y en cuanto a la restitución de tierras se acogerán aquellas personas que fueron despojadas de sus tierras a partir del 1 de enero de 1991.

El legislador pretende con esta ley brindar toda clase de ayudas a las víctimas, pues en el Art. 1 de esta hace mención a una serie de ayudas de carácter judicial, administrativa, social, económica, individual o colectiva las cuales serán ofrecidas a través de mecanismos y entidades especiales las cuales tienen como función primordial dar cumplimiento a los principios que gobiernan dicha ley, ellos son: la dignidad, buena fe, progresividad, gradualidad, sostenibilidad, publicidad, participación conjunta, complementariedad, prohibición de doble reparación y compensación. 
La víctima debe acreditar el daño sufrido por cualquier medio legalmente aceptado y probarlo de manera sumaria para que pueda ser ingresado al registro único de víctimas, lo expresado o presentado como prueba debe ser corroborado por la unidad administrativa especial para la atención y reparación integral de víctimas; esta se encarga de investigar y aceptar o denegar el ingreso a dicho registro.

La ley tiene como propósito crear un plan nacional de financiación, para lograr el "fin" encomendado que es el restablecimiento de los derechos a través de una indemnización, que tendrá lugar por el pago oportuno realizado por el victimario; pero cuando este no tenga como responder ya sea porque no tiene bienes o dinero el estado responderá subsidiariamente, pero en un monto no superior al estipulado por el reglamento de indemnización.

\section{ANÁLISIS DE LA LEY DE VICTIMAS Y RESTITUCIÓN DE TIERRAS. LEY 1448 DE 2011}

La ley de víctimas y restitución de tierras tiene varios vacíos jurídicos que generan una acción por omisión por parte del estado y que conllevan a la violación de la trilogía de derechos o desvirtuar el fin único por el cual fue creada la ley. Estos aspectos son:

- Se enmascaran derechos que son obligaciones inminentes del estado como acciones de restablecimiento. Osea el estado deja su responsabilidad a un lado, pues es claro en el Art. 9 que las medidas de atención, asistencia y reparación no implican reconocimiento alguno de responsabilidad estatal.

- En cuanto a la restitución de tierras los poseedores de buena fe se están quedando con las tierras, pues el campesino se queda con el título y el poseedor con la tierra. Ya que son tierras fértiles les parece mejor a estos quedárselas y engañar a los campesinos, en el caso de los indígenas se han identificado dos modalidades, la primera de ellas es retardar o negar la titulación de territorios, que se perfilan como zonas de interés económico. Por lo tanto no se titula el territorio ancestral como colectivo o resguardo, evitando realizar la consulta previa y cuando la realizan le preguntan a quienes no representan legítimamente a la comunidad afectada.

La segunda es la cooptación o constreñimiento por agentes externos legales o ilegales o por servidores públicos aliados con ellos para manipular las consultas y sus resultados en contra de los derechos colectivos y a favor de particulares.

- Según jurisprudencia constitucional la indemnización debe contribuir a superar el estado de vulnerabilidad de la víctima y su familia. Pero como aún existe conflicto armado, muchas veces las indemnizaciones que se les da a las víctimas cubre el daño causado, pero no desaparece el estado de vulnerabilidad, pues muchas víctimas que son resarcidas son un nuevo blanco de delitos origen del conflicto.

- Se propende a que las víctimas renuncien a muchos de sus derechos a cambio de una suma de dinero. 
- En cuanto a los menores victimarios será el estado quien asignará la indemnización subsidiaria, pero en cuanto al derecho a la verdad y memoria histórica se generaría impunidad.

- Una de las metas de la ley es la creación de un archivo sobre las violaciones a los derechos humanos e infracciones al derecho internacional humanitario, el cual debe ser creado dentro de los seis meses siguientes a la expedición de la ley y estará a cargo del centro de memoria histórica el cual será creado por el gobierno en un término que la ley no estipula como si lo hace con el archivo por lo tanto deja al arbitrio del gobierno al creación de este centro y a su vez generaría el incumplimiento de una de sus máximas como es la creación del archivo en un término de seis meses. (2011)

\section{MATERIALIZACIÓN DEL FENÓMENO DE LA DISCRIMINACIÓN POSITIVA EN LA LEY DE VÍCTIMAS Y RESTITUCIÓN DE TIERRAS}

Una de las controversias surgidas en las sociedades democráticas liberales es si con el reconocimiento de los grupos particulares (minorías) se genera una democracia antiliberal; relacionando esta controversia con el reconocimiento que hace el estado colombiano a los civiles víctimas del conflicto armado, surge la pregunta ¿se convierte el estado colombiano en una sociedad antiliberal o siendo más concretos se materializaría una discriminación positiva al reconocer y ofrecer trato preferencial a las víctimas del conflicto armado?, para responder la pregunta planteada tomare como referente teórico lo manifestado por Charles Taylor en su libro Multiculturalismo y política de reconocimiento. (Taylor, 2000)

En una sociedad democrática liberal como lo es Colombia se debe reconocer la identidad individual, no la identidad que representa un grupo, pues como Taylor (1992) manifiesta los humanos son únicos, son creativos por sí mismos y tienen un pensamiento que se basa en lo vivido individualmente, pensamiento que genera la creación de una identidad y un comportamiento autónomo.

Las víctimas del conflicto armado deben mirarse como hombres y mujeres individuales con una identidad autónoma al igual que los civiles no afectados por el conflicto, no se les debe sobreproteger solo debe el estado ayudarlos a superar la situación de vulnerabilidad en que se encuentran para dejarlos en el mismo estado de reconocimiento social que tienen los demás ciudadanos colombianos; la ley de víctimas en su texto normativo habla de preferencias. Pero por qué preferencias si estos ciudadanos tienen el mismo derecho y autonomía social que los demás.

En las democracias liberales se debe tener como referente el principio universalista (RECONOCIMIENTO DE DERECHOS UNIVERSALES) el cual hace referencia a que un estado y sus instituciones deben tratar a todos como iguales y respetar los derechos básicos sin importar que hagan o no parte de un grupo social o una minoría social; por lo tanto el estado no debe limitarse a reconocer solo a un grupo de colombianos sino de reconocer a todos por igual.

Partiendo de lo expuesto se concluye que se está materializando el fenómeno de la discriminación positiva, ya que se les está dando un trato preferencial a los civiles víctimas del conflicto después 
de ser incluidos en el registro único de víctimas y resarcidos los daños que les fueron causados, estos ciudadanos afectados deben ser tratados como los demás. Ya que cuando ha sido superada la situación de vulnerabilidad lo más justo es tratarlos como personas normales, se llamaría discriminación estigmatizarlos como grupo o minoría vulnerable porque ya dicho estado ha sido superado. $\mathrm{O}$ es que como no existen los presupuestos necesarios para lograr una protección total de los derechos vulnerados por parte del estado, este se toma la tarea de hacerlos sentir como minoría protegida a un después de haber transcurrido la etapa de resocialización.

\section{CONCLUSIONES}

\section{La investigación realizada generó las siguientes conclusiones:}

1) La flexibilidad del sistema jurídico colombiano se genera injusticia, al no aplicar la ley de manera rigurosa el sistema jurídico es fuente del detrimento de los derechos de las víctimas por lo tanto es necesario ajustar los principios de justicia.

2) La administración de justicia no está capacitada aun para lograr una verdadera protección de la trilogía de derechos ya que existen falencias y una prueba fehaciente de esto es la masacres en pueblo bello, Mapiripan entre otras en donde fue necesario acudir a un órgano internacional para que exigiera la protección a las víctimas de estos atentados. El estado no fue diligente fue negligente.

3) La ley de víctimas y restitución de tierras legaliza el despojo de las tierras a los campesinos pues son los poseedores de ellas, son quienes las están disfrutando y los campesinos no pueden aun hacer uso de ellas pues o no las titulando o existe una omisión por parte de las entidades a cargo por tanto no existe una garantía para las víctimas que quieren recuperar sus tierras; como ejemplo de esto es la lucha indígena por la recuperación de sus tierras y reconocimiento de sus resguardos y además la lucha con los poderosos inversionistas que buscan tierras para proyectos de grandes dimensiones (PNUD, 2011). Respecto y por un tema parecido la ONU hizo una recomendación al estado de crear mecanismos de protección y seguridad para las víctimas que han sido objeto de desalojo las cuales han sido devueltas y después de esto vuelven a ser desalojados por los mismos actores armados. (PNUD, 2011)

4) El estado debe ser respetuoso con los ciudadanos y evitar generar falsas esperanzas en las victimas, pues no debe crear leyes en las cuales busque satisfacer los deseos de actores sociales importantes; debe propender por el desarrollo social y mejorar el problema cultural que sacude el país el cual es originado por la mala educación que se brinda; el pueblo colombiano es sinónimo de ignorancia, hoy son pocos los que se pueden educar por tanto son pocos los que pueden defender sus derecho y muchos los que se dejan engañar.

5) Con la preferencia que manifiesta la ley de víctimas que se debe tener con los civiles víctimas del conflicto se materializa una discriminación positiva por parte del estado colombiano pues debe tener como referente el respeto por los derechos universales de sus ciudadanos y además tener en cuenta que cada individuo tiene una identidad autónoma por tanto las instituciones gubernamentales al aplicar sus políticas 
públicas debe ser deliberativo y no discriminativo al estigmatizar a grupos de ciudadanos como minorías o grupos en situación vulnerable.

\section{REFERENCIAS BIBLIOGRÁFICAS}

FLORIAN, H. (2007) "Debates y desafios de la ley de justicia y paz." Bogotá: Fondo Editorial.

HABERMAS, J. (1998) "Facticidad y Validez". Madrid: Trotta.

JURISTAS, C. C. (2012) "Anotaciones sobre la ley de justicia y paz, una mirada desde los derechos humanos." Bogotá: CCJ.

ONU. (2004) "Informe tipos de justicia transicional." New York: ONU.PNUD. (2011) "ABC de la ley de víctimas." Hechos y paz, 40.

QUEZADA, S. (2010) "Colombia y los desafios de la justicia transicional y restaurativa." Bogotá: Observatorio justicia transicional.

REPÚBLICA, C. d. (2011) Ley 1448. Bogotá, Colombia: Congreso de la República.

TAYLOR, C. (2000) "Multiculturalismo y política del reconocimiento". México: Fondo de cultura económica. 